\title{
PENERAPAN METODE ISHIHARA UNTUK MENDETEKSI BUTA WARNA SEJAK DINI BERBASIS ANDROID
}

\author{
Alvino Octaviano ${ }^{1}$ dan Andri Umbari ${ }^{2}$ \\ Teknik Informatika, Universitas Pamulang \\ JL. Surya Kencana No. 1, Pamulang, Tangerang Selatan-Indonesia \\ Email: ${ }^{1}$ alvinomail@gmail.com; ${ }^{2}$ andri.umbari@gmail.com
}

\begin{abstract}
ABSTRAK
Penglihatan warna merupakan salah satu fungsi penglihatan yang penting dalam kehidupan seharihari. Akan tetapi, tidak semua orang dikaruniai kemampuan penglihatan warna yang normal. Salah satunya adalah penderita defisiensi penglihatan warna atau lebih dikenal dengan istilah buta warna. Buta warna adalah suatu keadaan dimana seseorang tidak dapat membedakan warna tertentu yang bisa dibedakan oleh orang lain dengan mata normal. Tingkat mobilitas dan kesibukan saat ini membuat rendahnya kesadaran dan kurangnya pengetahuan masyarakat mengenai kelainan buta warna, serta melakukan tes buta warna sejak dini. Gangguan buta warna dapat diketahui dengan melakukan test buta warna menggunakan buku tes metode Ishihara. Penilitan ini bertujuan untuk membuat aplikasi tes buta warna yang mengimplementasikan Metode Ishihara dengan teknik penalaran maju (forward chaining). Jenis buta warna yang dapat di identifikasi pada aplikasi ini yaitu: penglihatan normal, buta warna parsial, dan buta warna total. Aplikasi ini dirancang berbasis android menggunakan bahasa pemrograman Java dan XML serta menggunakan metode Artificial Intellegence dilanjutkan dengan pengujian sistem dengan menggunakan metode black-box dan white-box. Dengan adanya aplikasi ini dapat disimpulkan bahwa aplikasi tes buta warna berbasis android dengan menggunakan metode Ishihara dapat mempermudah masyarakat untuk melakukan tes buta warna guna mengetahui gangguan penglihatan warna terhadap mata dengan hasil diagnosa yang dapat diperoleh secara langsung melalui smartphone android.
\end{abstract}

Kata kunci: Buta Warna, Metode Ishihara, Android.

\section{PENDAHULUAN}

Penglihatan warna merupakan salah satu fungsi penglihatan yang penting dalam kehidupan sehari-hari. Pekerjaan tertentu sangat membutuhkan kemampuan pembeda warna yang baik. Akan tetapi, tidak semua orang dikaruniai kemampuan penglihatan warna yang normal. Salah satunya adalah penderita defisiensi penglihatan warna atau lebih dikenal dengan istilah buta warna. Buta warna adalah suatu keadaan dimana seseorang tidak dapat membedakan warna tertentu yang bisa dibedakan oleh orang lain dengan mata normal. Biasanya seseorang dengan buta warna masih dapat mengenal warna, buta warna merupakan kelainan genetik atau bawaan yang diturunkan dari orang tua kepada anaknya.

Tingkat mobilitas dan kesibukan saat ini membuat rendahnya kesadaran dan kurangnya pengetahuan masyarakat mengenai kelainan buta warna, serta melakukan tes buta warna sejak dini. Buta warna umumnya dianggap lebih banyak terdapat pada laki-laki dibanding perempuan dengan perbandingan 20:1. Buta Warna mempengaruhi $13 \%$ populasi umum. Saat ini di
Eropa sekitar $8-12 \%$ pria dan $0,5-1 \%$ wanita menderita buta warna. Penelitian lain menyatakan 1 dari 12 orang pria menderita buta warna. Sedangkan wanita hanya 1 dari 200 orang saja yang menderita bura warna [4].

Dokter mata melakukan tes dengan menggunakan suatu buku tes, buku tersebut dikenal dengan Ishihara tes, yang terdiri dari plat atau lembaran yang didalamnya terdapat titiktitik dengan berbagai warna dan ukuran. Titik tersebut membentuk lingkaran, warna titik itu dibuat sedemikian rupa sehingga orang buta warna tidak akan melihat perbedaan warna seperti yang dilihat orang normal.

Buku tes Ishihara berisi cetakan gambar pseudo-isochromatic akan mengalami perubahan warna karena seiring bertambahnya usia buku, warna yang ada pada pseudo-isochromatic akan pudar atau kusam jika terlalu lama disimpan, kekusaman warna akan merubah keaslian plat untuk alat uji sehingga akan mempengaruhi keakuratan hasil tes [3]. 


\section{LANDASAN TEORI \\ Buta Warna}

Buta warna adalah suatu kelainan yang disebabkan ketidakmampuan sel-sel kerucut mata untuk menangkap suatu spectrum warna tertentu yang disebabkan oleh faktor genetis. Buta warna merupakan kelainan genetika yang diturunkan dari orang tua kepada anaknya, kelainan ini sering juga sebut sex linked, karena kelainan ini dibawa oleh kromoson X. Artinya kromosom Y tidak membawa faktor buta warna. Hal inilah yang membedakan anatara penderita buta warna pada laki-laki dan perempuan. Seorang perempuan terdapat istilah 'pembawa sifat', hal ini menunjukan ada satu kromosom $\mathrm{X}$ yang membawa sifat buta warna. Perempuan dengan pembawa sifat, secara fisik tidak mengalami kelainan buta warna sebgaimana wanita normal pada umumnya, tetapi wanita dengan pembawa sifat berpotensi menurunkan faktor buta warna kepada anaknya kelak. Apabila kedua kromoson $\mathrm{X}$ mengandung faktor buta warna maka seorang wanita tersebut menderita buta warna [2]

\section{Metode Ishihara}

Tes Ishihara dikembangkan oleh Dr.Shinobu Ishihara pada tahun 1917, hingga saat ini metode Ishihara masih menjadi salah satu pilihan utama hampir di semua Negara untuk mengidentifikasi seseorang yang mengalami buta warna. Tes metode Ishihara adalah tes yang digunakan untuk mendeteksi gangguan persepsi warna, berupa tabel warna khusus berupa lembaran pseudoisokromatik (plate) yang disusun oleh titik-titik dengan kepadatan warna berbeda yang dapat dilihat dengan mata normal, tapi tidak bisa dilihat oleh mata yang mengalami defisiensi sebagian warna. Plate adalah warna primer dengan dasar warna yang hampir sama atau abu-abu. Tes Ishihara secara relative dapat dipercaya dalam membedakan antara defisit (lemah) warna merah dan defisit (lemah) warna hijau [1].

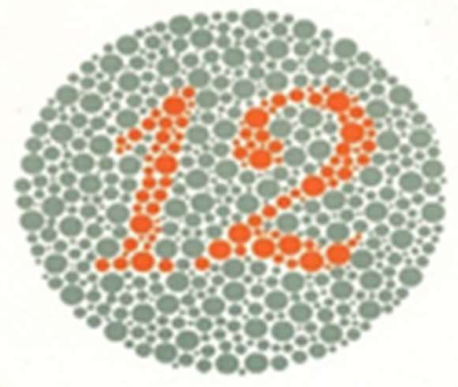

Gambar 2.1 Plate Ishihara

\section{ANDROID}

Android merupakan sistem operasi perangkat mobile yang berbasis linux dan bersifat terbuka atau opensource dengan lisensi GNU yang dimiliki Google. Ponsel Android akan selalu disempurnakan. Tidak seperti sistem tertutup lainnya yang bergantung pada produsen untuk menciptakan inovasi, ini berarti bahwa Google maupun mitranya dapat terus membuat penyempurnaan [5].

\section{PEMBAHASAN FlowchartSistemTesButaWarnaMetode Ishihara}

Citra Ishihara yang biasa digunakan memiliki warna dominan antara merah dan hijau sehingga hanya dapat digunakan untuk mengetahui buta warna parsial terhadap warna merah-hijau. Butra warna parsial terhadap warna biru-kuning akan sulit diketahui dari tes ini karena citra Ishihara sedikit sekali menggunakan warna biru dan kuning. Dengan demikian fitur tes buta warna yang diimplementasikan terhadap warna tipe protan kuat (kelemahan penglihatan terhadap warna merah), deutan kuat (kelemahan penglihatan terhadap warna hijau), buta warna total, normal dan apabila kondisi di atas tidak ada yang terpenuhi atau dengan kata lain ada kemungkinan pengguna adalah tipe protan lemah, deutan lemah, atau tritan (kelemahan terhadap warna biru), maka sistem akan mengenali pengguna sebagai buta warna parsial. Berikut ini flowchart tes buta warna dengan metode ishihara. 


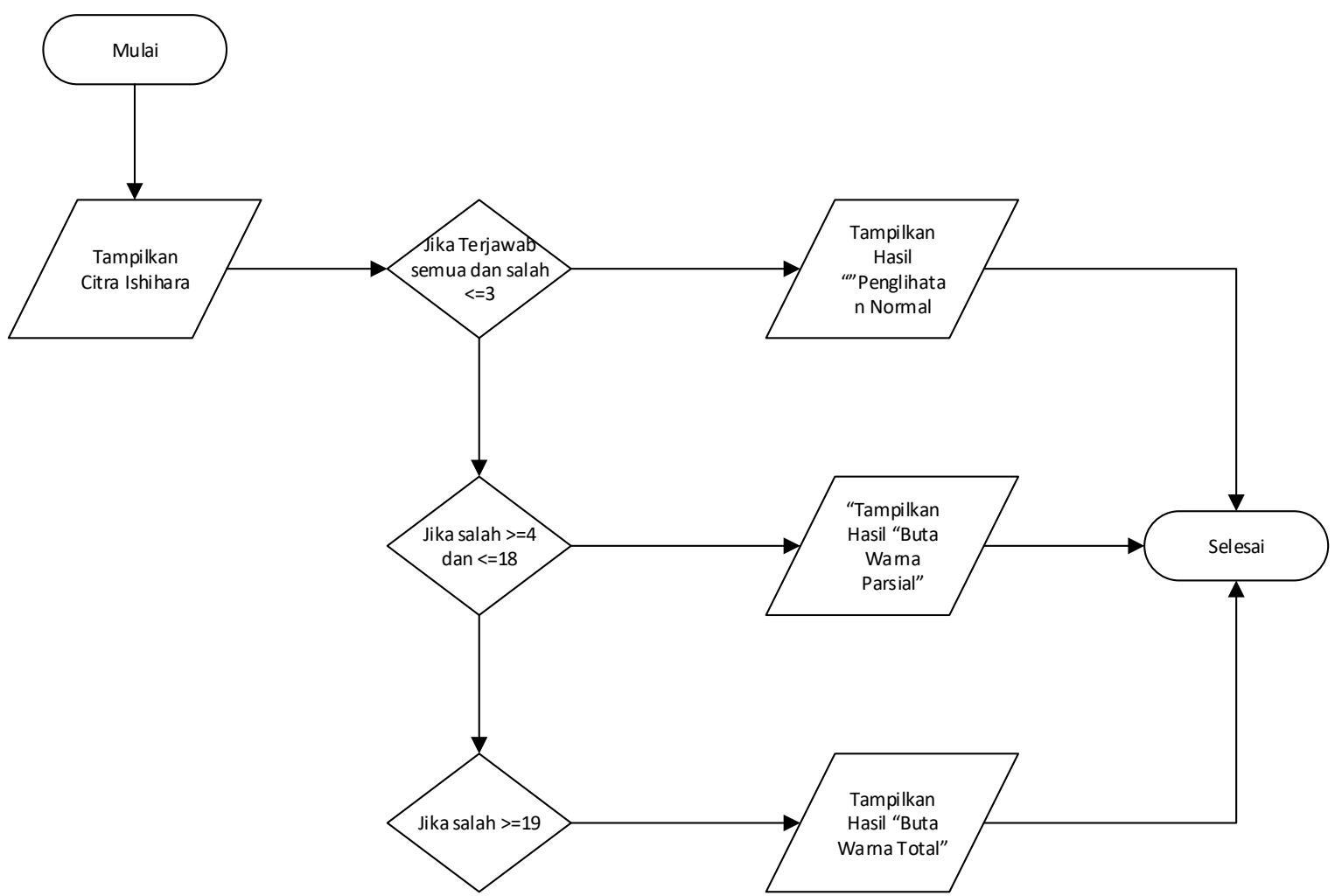

Gambar 3.1 FlowchartSistemTesButaWarna

Use CaseDiagramAplikasiTesButaWarna

Use case Diagram digunakan untuk mewakili fungsionalias dari sistem. Diagram ini menggambarkan interaksi antara pengguna, yang diwakili dengan notasi aktor, dengan sistem untuk mencapai tujuannya, Use Case Diagram untuk sistem penerapan metode Ishihara untuk mendiagnosa buta warna yang akan dibuat terdapat pada gambar berikut ini

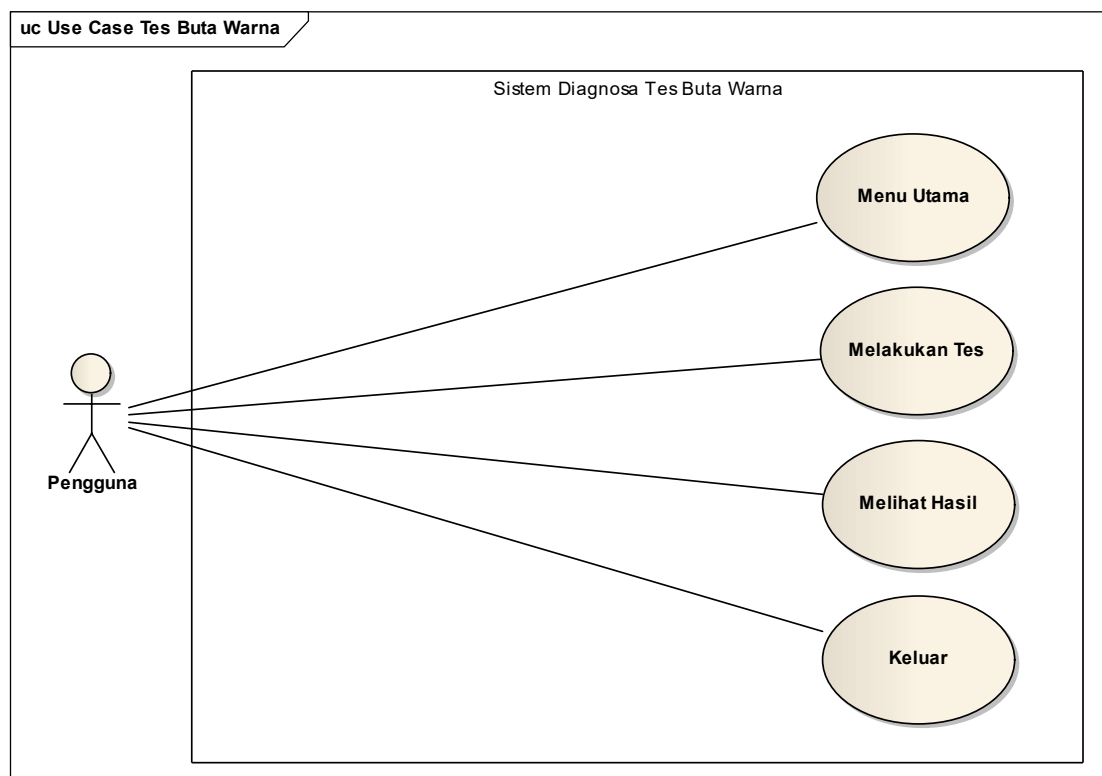

Gambar 3.1. Use Case Diagram ApikasiButaWarna 
Activity Diagram SistemTesButaWarna

Activity diagram digunakan untuk memodelkan aliran kerja proses dalam bentuk simbol untuk menspesifikasikan bagaimana sistem akan mencapai tujuan.

\section{Activity Diagram MelakukanTesButaWarna}

Alur proses acitivity diagram melakukan tes ini dimulai pada saat pengguna menyentuh tombol mulai tes. Pengguna akan dihadapkan dengan plat metode Ishihara dan diminta menuliskan jawaban sesuai dengan angka yang mereka lihat. Berikut ini activity diagram melakukan tes.

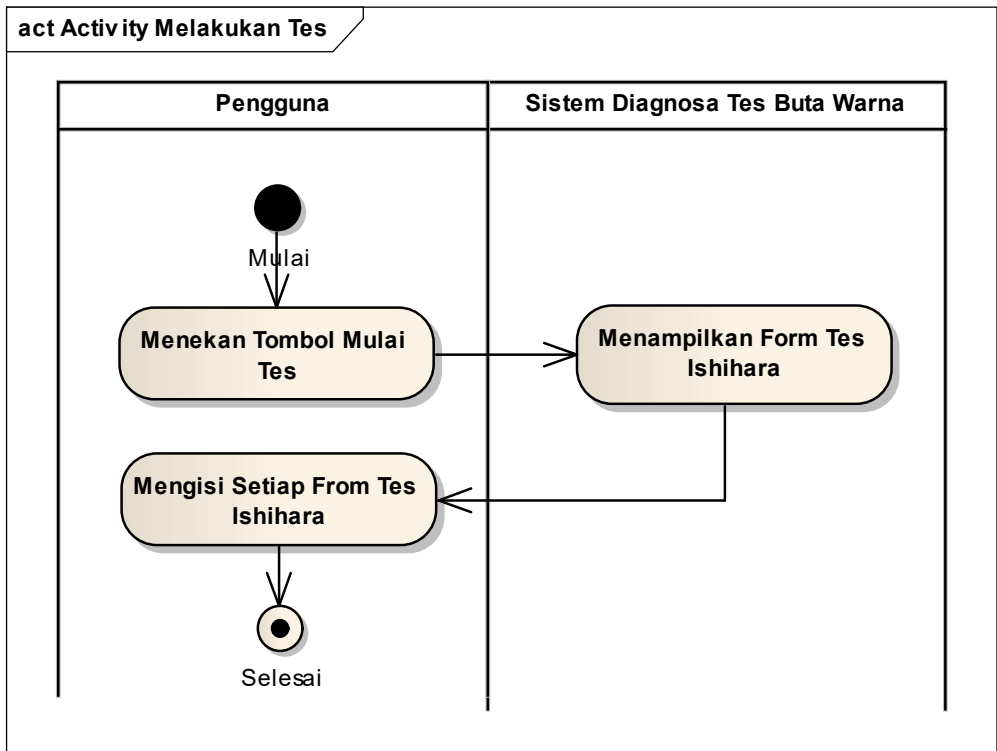

Gambar 3.3 Activity Diagram Melakukan Tes Buta Warna

\section{Activity DiagramHasilTesButaWarna}

Alur proses activity diagram hasil tes ini memberikan hasil diagnosis dari pertanyaan yang telah dijawab pengguna, setelah pengguna selesai menjawab pertanyaan hasil diagnosis akan langsung keluar. Berikut ini activity diagram hasil tes.

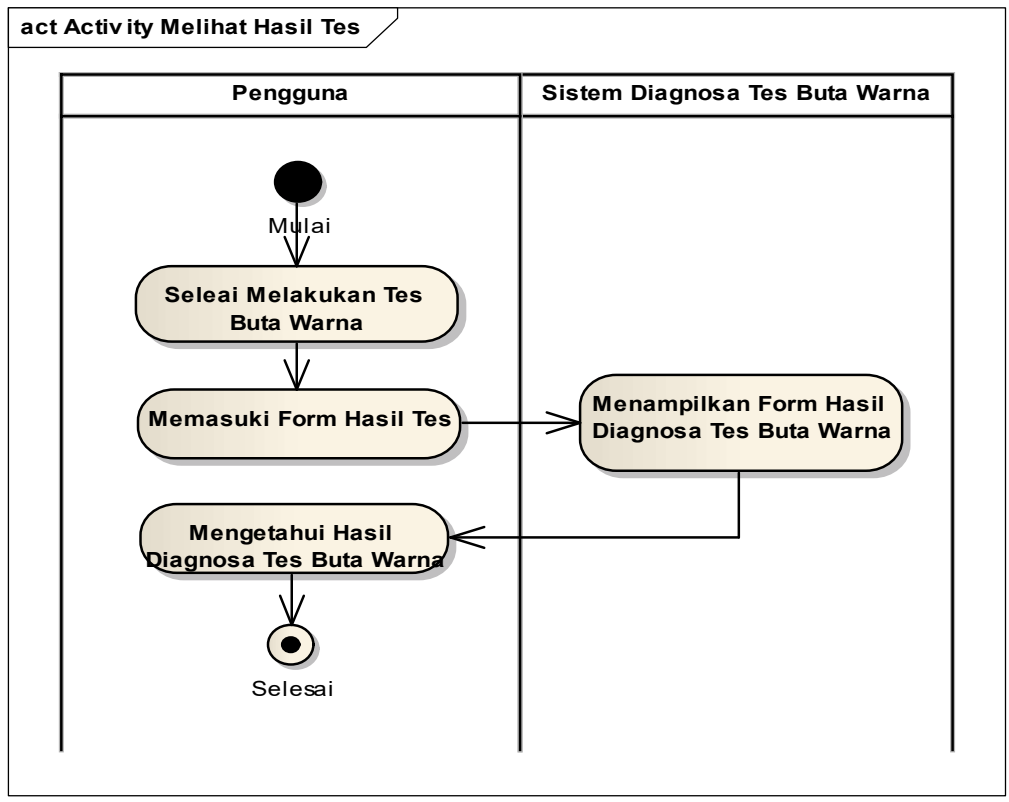

Gambar 3.4 Activity Diagram Hasil Tes Buta Warna 


\section{Implementasi}

Setelah sistem dianalisa dan dirancang, maka tahap selanjutnya adalah implementasi. Tahapan implementasi merupakan tahap yang dilakukan setelah analisis dan perancangan aplikasi. Pada tahap ini hasil analisis dan perancangan diterjemahkan kedalam bahasa pemrograman sehingga menghasilkan suatu aplikasi. Pengimplementasian perangkat lunak ini meliputi persiapan, pembuatan perangkat lunak, serta pengkodingan.

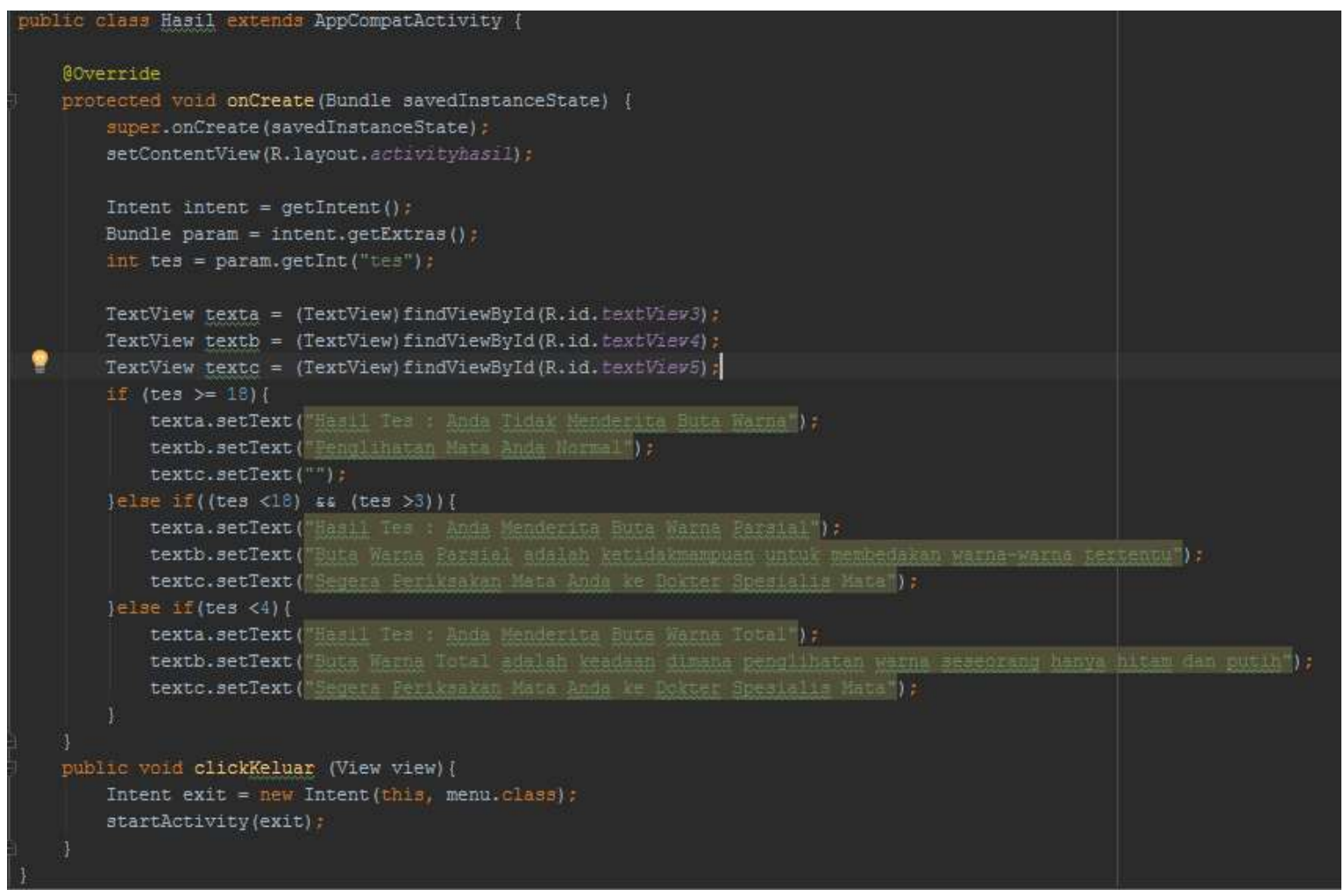

Gambar 3.5 Kode Program untuk Menentukan Jenis Buta Warna

\section{ImplementasiAntarMuka}

Antarmuka (interface) adalah salah satu layanan yang disediakan sistem operasi sebagai sarana interaksi antara pengguna dengan sistem operasi, antarmuka (interface) adalah komponen sistem operasi yang bersentuhan langsung dengan pengguna, terdapat dua jenis antarmuka, yaitu Command Line Interface (CLI) dan Graphical User Interface (GUI) Berikut ini adalah implementasi dari rancangan interface yang telah dibuat sebelumnya:

a. Tampilan Halaman Tes Aplikasi Buta Warna Metode Ishihara

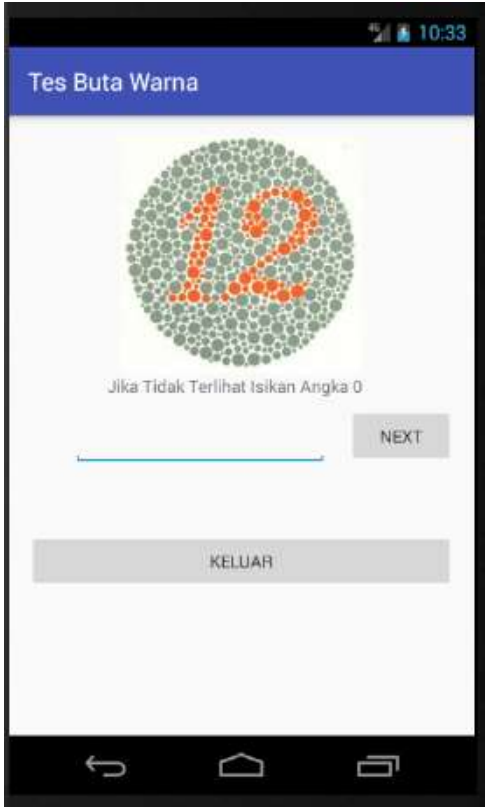

Gambar 3.6 Tampilan Halaman Tes Buta Warna Metode Ishihara 
Pada halaman ini pengguna akan ditampilkan form tes diagnosa buta warna dengan metode Ishihara sebanyak 21 citra Ishihara

b. Tampilan Halaman Hasil Tes Buta Warna Metode Ishihara

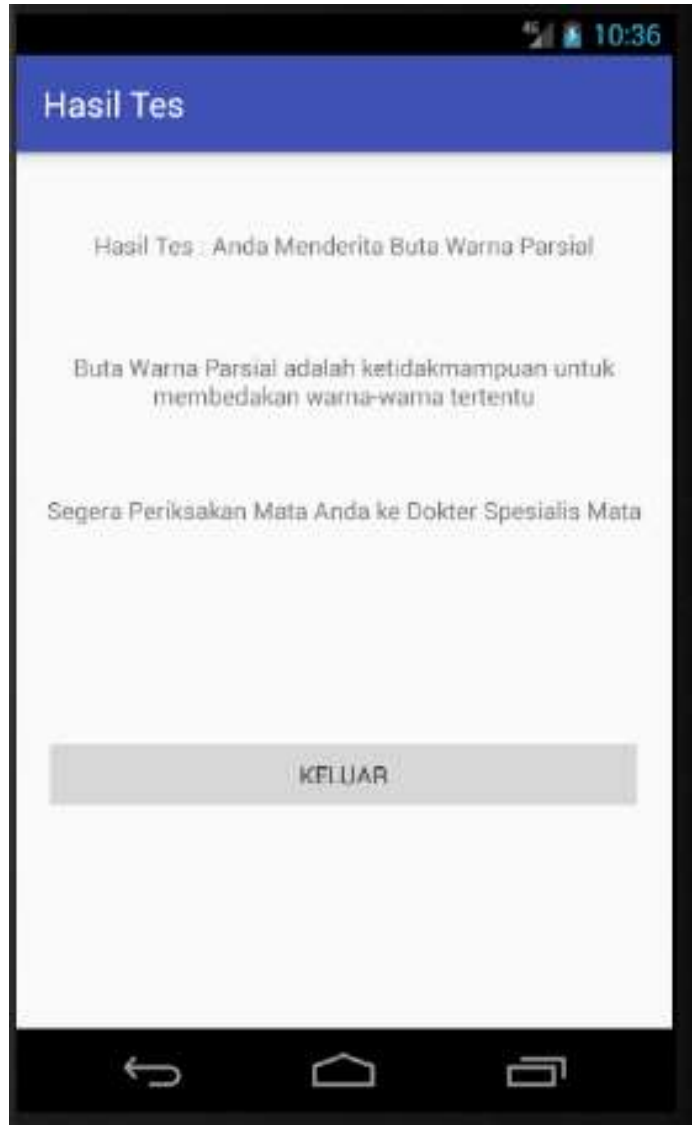

Gambar 3.7 Tampilan Halaman Hasil Tes Buta Warna Metode Ishihara

Pada halaman ini pengguna yang telah selesai melakukan tes diagnosa buta warna dan berhasil menjawab beberapa citra Ishihara dengan ketentuan salah lebih dari 4 dan tidak lebih dari 18 akan melihat hasil dari tes tersebut.

\section{Pengujian White Box}

Pengujian White Box adalah suatu metode desain test case yang menggunakan struktur control desain procedural untuk memperoleh test case. Dengan menggunakan metode pengujian white box, perekayasa sistem dapat melakukan test case yang dapat:

1. Memberikan jaminan bahwa semua jalur independen pada suatu modul telah digunakan paling tidak 1 kali.
2. Menggunakan semua keputusan logis pada sisi true dan false.

3. Mengeksekusi semua loop (perulangan).

4. Operasional pengguna aplikasi.

Di bawah ini merupakan Grafik alir dari aplikasi tes buta warna.

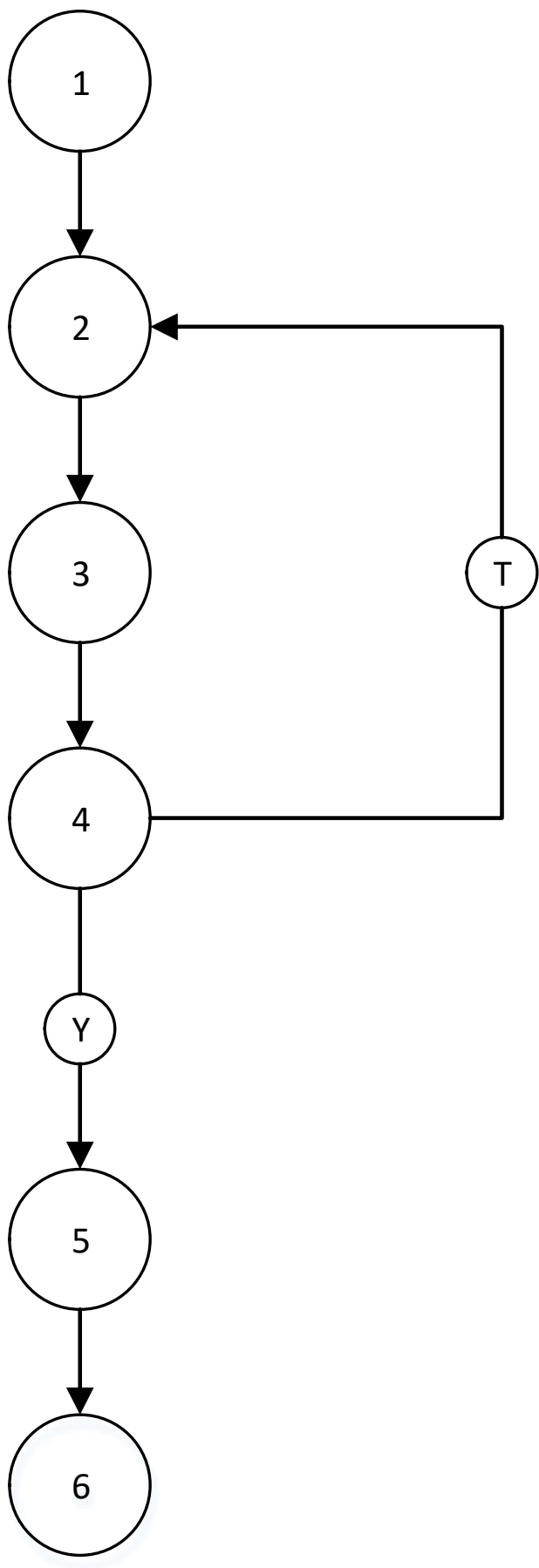

Gambar 3.8 Grafik Alir Aplikasi Tes Buta Warna 
protected void onCreate(Bundle savedInstanceState)\{ super.onCreate(savedInstanceState);

setContentView(R.layout.splash);

Thread timer $=\operatorname{run}()->\{$

Trys

Sleep (3000);

\}catch (InterruptedException e) \{

e.printStackTrace();

ifinally\{

Intent $i=$ new Intent(Splash.this,menu.class);

startActivity (i);

;

Timer.start();

\}

Protected void onCreate(Bundle savedInstanceState)\{ Super.onCreate (savedInstanceState);

setContentView(R.layout.activitymenu);

\}

Public void clickTes (View view)

Intent tes = new Intent(this, TesActivity.class);

startAcitivity(tes);

\}

protected void onCreate(Bundle savedInstanceState)\{ super.onCreate(savedInstanceState);

setContentView(R.layout.actitvitytes);

init(1);

\}

Intent intent $=$ new Intent(TesActivity.this, Hasil.class);

Bundle param = new Bundle();

Param.putInt("tes", tes);

Intent.putExtras(param);

startActivity(intent);

;

Public void clickExit (View view)

Intent exit = new Intent(this, menu.class);

startActivity(exit);

\}

Protected void onCreate (Bundle savedInstanceState) \{

Super.onCreate(savedInstanceState);

setContentView(R.layout.activityhasil);

public void clickKeluar (View view) \{

Intent exit = new Intent(this, menu.class);

startActivity(exit);

\}

Kompleksitas siklomatis (pengukuran kuantatif terhadap kompleksitas logis suatu program) dari grafik alir dapat diperoleh perhitungan:
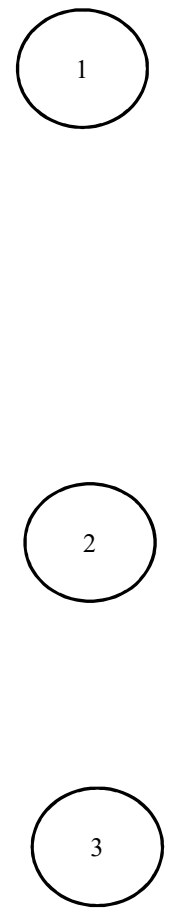

4

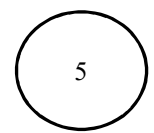

6 
$\mathrm{N}=$ Jumlah simpul grafik alir yang ditandakan dengan gambar lingkaran

Sehingga kompleksitas siklomatisnya

$\mathrm{V}=6-6+2=2$

Basis set yang dihasilkan dari jalur independent secara linier adalah jalur sebagai berikut :

$1-2-3-4-5-6$
$1-2-3-2-4-5-6$

\section{Pengujian Black Box}

Dalam pengujian berikutnya dilakukan untuk memastikan bahwa suatu event atau masukan akan menjalankan proses yang tepat dan menghasilkan output sesuai dengan rancangan yang dibuat.

Tabel 3.1 Pengujian Black Box

\begin{tabular}{|c|c|c|c|}
\hline Input/Event & Proses & Output & Kesimpulan \\
\hline $\begin{array}{l}\text { Menampilkan } \\
\text { Splash Screen } \\
\text { Selama } 3 \text { detik }\end{array}$ & $\begin{array}{l}\text { Protected void onCreate (Bundle } \\
\text { SavedInstancState)\{ } \\
\text { Super.onCreate (savedInstanceState); } \\
\text { setContentView(R.layout.splash); } \\
\text { Thread timer = new Thread()\{ } \\
\text { Public voin run()\{ } \\
\text { Try\{ } \\
\text { Sleep(3000); } \\
\text { \}catch(InterruptedException e)\{ } \\
\text { e.printStackTrace(); } \\
\{\end{array}$ & $\begin{array}{l}\text { Menampilkan } \\
\text { splash screen } \\
\text { selama } 3 \text { detik }\end{array}$ & Sesuai \\
\hline $\begin{array}{l}\text { Menampilkan } \\
\text { Menu Utama }\end{array}$ & $\begin{array}{l}\{ \\
\text { Intent } i=n e w \text { Intent (splash.this, menu.class); } \\
\text { startActivity(i); }\end{array}$ & $\begin{array}{c}\text { Menampilkan } \\
\text { menu utama }\end{array}$ & Sesuai \\
\hline $\begin{array}{c}\text { Tombol Mulai } \\
\text { Tes }\end{array}$ & $\begin{array}{l}\text { Public void clickTes (View view) } \\
\text { Intent tes = new Intent(this, TesActivity.class); } \\
\text { startActivity(tes); }\end{array}$ & $\begin{array}{l}\text { Memulai tes } \\
\text { Ishihara }\end{array}$ & Sesuai \\
\hline Tombol About & $\begin{array}{l}\text { Public void clickAbout (View view); } \\
\text { Intent about = new Intent (this, about.class); } \\
\text { startActivity(About); }\end{array}$ & $\begin{array}{c}\text { Menampilkan } \\
\text { About }\end{array}$ & Sesuai \\
\hline $\begin{array}{l}\text { Menampilkan } \\
\text { hasil tes } \\
\text { Ishihara }\end{array}$ & $\begin{array}{l}\{ \\
\text { Intent intent = new Intent(TesActivity.this, } \\
\text { Hasil.class); } \\
\text { Bundle param = new Bundle(); } \\
\text { Param.putInt("tes", tes); } \\
\text { Intent.putExtras(param); } \\
\text { startActivity(intent); }\end{array}$ & $\begin{array}{l}\text { Menampilkan } \\
\text { hasil tes }\end{array}$ & Sesuai \\
\hline $\begin{array}{l}\text { Tombol } \\
\text { kembali ke } \\
\text { menu utama }\end{array}$ & $\begin{array}{l}\text { Public void clickExit (View view) } \\
\text { Intent exit = new Intent(this, menu.class); } \\
\text { startActivity(exit); } \\
\}\end{array}$ & $\begin{array}{l}\text { Kembali ke } \\
\text { menu utama }\end{array}$ & Sesuai \\
\hline
\end{tabular}

\section{KESIMPULAN}

Berdasarkan hasil studi yang telah dilakukan maka dapat disumpulkan sebagai berikut:

a. Penelitian ini telah berhasil menghasilkan sistem pengujian jenis buta warna metode
Ishihara pada smartphone Android yang dapat digunakan oleh pengguna untuk mendeteksi buta warna secara dini dengan tampilan dan navigasi yang user friendly dengan hasil tes yang dapat diketahui secara langsung yang dibangun dengan 
menggunakan Java for Android dan IDE Android Studio 2.2.3.

b. Dari hasil pengujian yang telah dilakukan oleh pakar dr. Ade Shynta Amelia, Sp.M dapat diketahui bahwa aplikasi tes buta warna metode Ishihara berbasis Android dengan 21 plate citra Ishihara dapat mengidentifikasi penglihatan normal, buta warna parsial dan buta warna total.

\section{SARAN}

Untuk mengembangkan aplikasi ini agar makin memberikan manfaat bagi penggunanya maka ada beberapa hal yang bisa dijadikan bahan kajian lebih lanjut yaitu:

a. Untuk mengembangkan aplikasi ini agar makin memberikan manfaat bagi penggunanya maka ada beberapa hal yang bisa dijadikan bahan kajian lebih lanjut yaitu:

b. Memberikan batas waktu tertentu untuk menjawab pertanyaan yang ada pada aplikasi ini.

\section{DAFTAR PUSTAKA}

[1] Dhika, R. V., Ernawati, \& Andreswari, D. (2014). Aplikasi Tes Buta Warna Dengan Metode Ishihara Pada Smartphone Android. Jurnal Pseudocode, Volume 1 Nomor 1, Februari 2014, ISSN 2355 - 5920.

[2] Hartono, R. C. (2013). Sistem Pakar Diagnosa Penyakit Buta Warna Berbasis Android. Sebuah Kajian Pustaka, 120-126.

[3] Murti, H., \& Santi, R. C. (2011). Aplikasi Pendiagnosa Kebutaan Warna dengan Menggunakan Pemrograman Borland Delphi. Jurnal Teknologi Informasi DINAMIK Volume 16, No.12, Juli, 160-170.

[4] Rahmadi. (2009). Penentuan Tingkat Buta Warna pada Metode Ishihara. Padang: Universitas Andalas.

[5] Rahmawati, S. (2014). Pengembangan Media Pembelajaran Matematika Basis Android pada Peluang untuk Siswa SMK. Jakarta: Universitas Islam Negeri Syarif Hidayatullah Jakarta. 